\title{
Study of Experiment Education Quality Promotion by Building Appointment Management Platform
}

\author{
Xiaoyan Deng Zhimeng Zhang Yancong Shi \\ College of Electric and Electronic Engineering, Shijiazhuang Tiedao University, \\ Shijiazhuang, 050043, China
}

\begin{abstract}
The main aim of this paper is exploring a new laboratory teaching mode learned from the office automation in recent years. Firstly, analyzing the real requirement in experiment teaching, we build up an open appointment platform for instructors and students. Based on it, we could manage the experiment projects and preserve the instruments in time. Secondly, for the sake of humanistic management, we set up a whole mechanism to guarantee it. That is, labs are opened by experiment centre, experiment projects are opened by the selected instructors, and students choose them finally according to their own arrangement. From the operating results we can see that this mode helps our laboratory management in some extent.
\end{abstract}

Keywords: Appointment management, Network platform, Cooperative spirit

\section{Introduction}

Practical education is one of significant part for higher education. Therefore, both the construction level and management level have great influence upon the quality of those graduates directly. At present, open Laboratory, started from physics experiment innovation in USA in the 1960s, is paid more and more attention by internal colleges [1-2]. In this mode, labs are open to students all day long. They may make choice of suitable time to finish the selected experiment projects for their major. Teachers in laboratory are not presenters any more, but counselors to them.

\section{Purpose and meaning analysis of building appointment platform}

Our electronic engineering experiment centre undertakes all experimental education segments in electricity basic subjects and specialized subjects. Due to electricity curriculum's character itself, pupils often make mistake in their experiment project. As we know, violation of operational requirement is one of the causes to components damage. Furthermore, because of so much experiment projects taken in the centre, effective management to instruments and equipments is a big problem. However, traditional management has many problems such as information recording, equipment maintaining, etc. By the aid of campus network resource and office automation technology, this new management mode has more advantage than that.

Combined with the reality of Shijiazhuang Tiedao Universiyt, we explored this open experimental management system since 2010. By making full use of information technology and campus 
network resource, we build up an open management platform for experimental education. Besides, we put almost all special courses with open experiment projects into it step by step. Finally, we reach the result that students are familiar with the procedure of appointed experiment, teachers grasp their operation work, and the college knows about how the experiment centre goes.

\section{Management mode analysis}

We open experiment appointment to make a platform for students. And they can improve their practical operation ability and their potential exploration creativity. Moreover, combined with the management demand of practical education, we use this system to realize uniform management for instruments, students, and instructors.

In this system, the experiment projects in the course are the core units. Fig.1 presents that how they contact with each other.

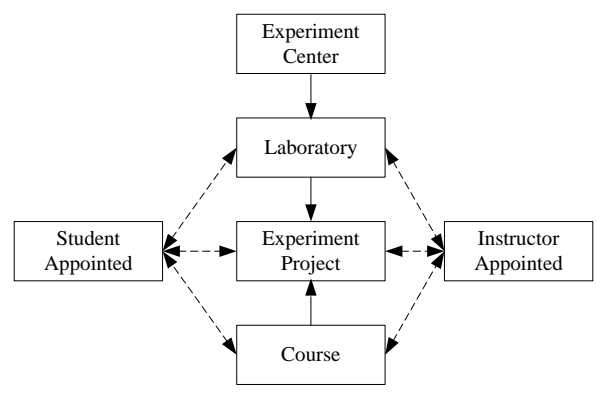

Fig. 1: Relationship of laboratory, experiment project, student, instructor, and course.

The following will explain how it works. During the platform running period, students are related to instructors by the course option. Moreover, the course is related to the specific laboratory using experimental project directly. So, via the experimental project item, both students and instructors could gain their own la- boratory room ID information appointed at the platform. Here, we use dash line to show their indirect relation. Furthermore, instructors may record the equipments' abnormal condition at their classroom, which will help the experiment centre to maintain them in time. It will guarantee the equipment availability, and ensure the following projects to open smoothly. Finally, the experiment centre opens each laboratory in the provided period only. Students may choose their own appropriate time to finish the experiment project. The main purpose is that we try our best to make the people-oriented management under the condition of normal teaching management unaffected.

From the actual running state we can see that this open mode enhances greatly students' time flexibility. Therefore, learning activity of students enhances greatly. Compare with before, the randomness of students' co-operators is raised. Correspondingly, it is put forward to them higher demand, such as operation skill and analysis ability. It may help students to overcome their inertness. At the same time, until the period of the course plan end, students may be in multiple groups. Their spirit of team cooperation is cultivated invisibly. All of those will help them to future work.

\section{Designation of open appointment platform}

We believe that, reasonable and effective organization is the successful guarantee to open appointment experiment. Therefore, combined with our college's characteristic, we set up the open experiment appointment management platform written by PHP + MySQL, the widely used development environment. We make use of both database management technology and WEB development technology. Moreover, open source code save much of our construction cost and maintenance 
cost, improve the construction speed. At present, we promote the efficiency, realize office automation in experimental teaching management.

Next, we'll show that how the management operation works, such as information collection and collation. As we all know, database technology has very important meaning to network platform reliable running. On the other hand, our education administration department employs teacher course summary table and experiment project table to manage both theoretical education and practical education. To facilitate the bulk import, we design two datasheet with the same fields like that. We omit the student info table and teacher info table because we use the same authentication way, namely school IC card.

Fig.2 shows how the management platform is going on. Firstly, the experiment centre opens the labs permission. Secondly, instructors appoint the experiment project base on syllabus requirement. Finally, students choose the specific appointed experiment project.

Here, we'll explain that how it works. At the beginning, administrator of the experiment centre opens the appointment permission in the specified time interval. when the labs are open, instructors may browse the labs' employ state, and choose according to their teaching arrangement. Once the appointment record taken place, it will be recorded in the teacher appointment info table. Correspondingly, the appointed lab won't be appointed again at the same time. Finally, students will browse the course, then they could appoint the given experiment project. This appointment record will be stored in the student appointment info table. When the appoint info is passed through, it also won't dismiss again except the administrator changed.

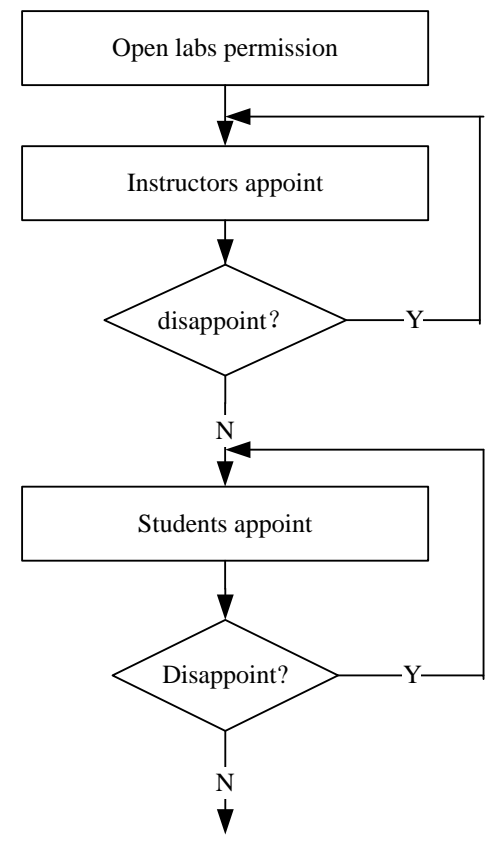

Fig. 2: Logical relationship of scheme used in the appointment management platform.

\section{Conclusions}

We accumulate the following experience in the practical teaching segment. We think that the new management mode breakdown the original one based on administrative class as a unit. After one appointed the experiment, his co-operator will become unknown. The original situation is improved in some extent, which has benefit for their team cooperative spirit more or less. We also manage equipment, student, and teacher together, which facilitates the practice of open experimental process. We have the sole target to cultivate high-quality practical talents. Under this appointed management platform, we build up a monitor system for experimental teaching and improve the assessment mechanism. Besides, we construct an innovation practical environment to cultivate the students' creativ- 
ity and team cooperative spirit. Their motivation is mobilized, which will help to improve their professional knowledge and hand-on skill. The most important thing is that the motivation we build up open experiment is not to see the final experiment result only, but to increase their cognitive theory learning in the classroom. By operating themselves, they could combine the knowledge in classroom into their experiment project. Even more, they maybe modify some procedure to test their idea. It will help to promote the transformation of their hidden knowledge into explicit knowledge.

We would like to thank the Educational Research Foundation of Shijiazhuang Tiedao University (110218) for funding this stduy.

\section{References}

[1] Xu Youquan, Li Renfa, "Design and implementation of the opening lab management system based on web," Research and Exploration in Laboratory, pp. 64-66, 2007.

[2] Jiang Hao, Lu Zhifeng, "Design and realization of open laboratory's management system," Research and Exploration in Laboratory, pp. 110- 112, 2010.

[3] Chang Wenying, "Research on the security management system of open chemical experiment in university," Laboratory science, pp. 190-193, 2011. 